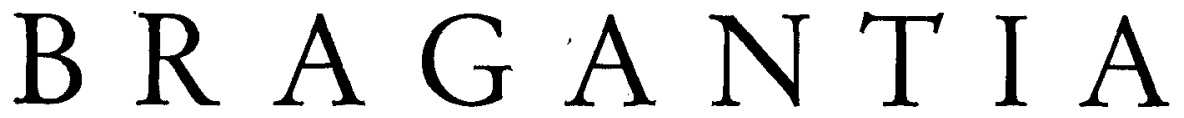

Boletim Científico do Instituto Agronômico do Estado de São Paulo

\title{
EFEITOS DA COBERTURA E DA INCORPORAÇÃO AO SOLO, IMEDIATAMENTE ANTES DO PLANTIO, DE DIFERENTES FORMAS DE MA- TÊRIA ORGÂNICA NÃO DECOMPOSTA, NA CULTURA DO FEIJOEIRO $\left({ }^{1}\right)$
}

Shiro Miyasaka, engenheiro-agrônomo, Seção de Leguminosas, A. PAES DE CAMARgo, engenheiro-agrônomo, Seção de Climatologia, RoMeU INForZATo, engenheiro-agrônomo, Seção de Fisiologia, TosHo IGuE, engenheiro-agrônomo, Seção de Estatística e Experimentação, Instituto Agronômico

\section{SINOPSE}

Foram estudados o comportamento da massa vegetal não decomposta de leguminosas e de gramíneas e seus efeitos, quando incorporada ao solo antes do plantio do feijão.

A incorporação ao solo de massa vegetal não decomposta acarretou: a) maior retenção de umidade e menor variabilidade térmica do solo, embora em menor grau que no solo com cobertura morta ("mulch"); $b$ ) tendência para formação de maior número de nódulos, principalmente quando a incorporação é de gramínea; c) aumento no teor de potássio nas fôlhas, no desenvolvimento da parte vegetativa e radicular e na produção de sementes do feijoeiro. Estes efeitos foram particularmente significativos quando da aplicação de soja perene, quer incorporada, quer em cobertura.

\section{1 - INTRODUÇ.̃̃O}

Bons resultados, geralmente com aumentos significativos de rendimento, têm sido observados com a cobertura morta ("mulch"), especialmente em regiões tropicais e subtropicais $(2,7)$. Poucas são, contudo, as referências à incorporação ao solo de matéria orgânica recém-cortada e seus efeitos em culturas anuais ou perenes.

Estudo preliminar, realizado por Miyasaka e outros (9), mostrou que uma massa vegetal não decomposta, constituída de $50 \%$ de soja perene (Glycine javanica L.) e 50\% de capim gordura (Melinis minutiflora Beauv), incorporada ao solo na véspera do

(1) Aspectos quimicos dêste trabalho foram apresentados ao $\mathrm{X}$ Congresso Brasileiro de Ciência do Solo, realizado em Piracicaba, no período de 19 a 30 de julho de 1965. Recebido para publicação em 24 de junho de 1966. 
plantio de feijão, trouxe apreciável aumento de produção de sementes dessa leguminosa. Guazelli (6), em Patos, Estado de Minas Gerais, e Miyasaka e outros (8), no Estado de São Paulo, mostraram efeitos favoráveis da incorporação de Crotalaria juncea L. em estado verde, imediatamente antes do plantio de feijão, sôbre o rendimento dêste.

Faltam, no entanto, informações sôbre o comportamento de massa verde ou sêca, não decomposta, de leguminosa ou de gramíneas, quando incorporada ao solo antes do plantio de feijão, quer do ponto de vista físico, químico ou biológico.

Visando contribuir ao estudo da questão, foi instalado um experimento para investigar os efeitos da espécie da matéria orgânica empregada e da forma de sua aplicação, cujos resultados. são aqui relatados.

\section{2 - MATERIAL E MÉTODO}

A experiência foi conduzida no período de 17 de março a 7 de junho (safra da sêca) de 1965, em Campinas, na Estação Experimental do Instituto Agronômico, em solo Latosol Roxo B. (terra-roxa-misturada), cuja análise $\left({ }^{2}\right)$ revelou o seguinte:

$\begin{array}{ll}\mathrm{pH} & =4,20 \\ \mathrm{~N} & =0,14 \% \text { em } 100 \mathrm{~g} \text { de solo sêco } \\ \mathrm{K}^{+} & =0,12 \text { e.mg por } 100 \mathrm{~g} \text { de solo sêco } \\ \mathrm{Ca}^{++} & =1,50 \text { e.mg por } 100 \mathrm{~g} \text { de solo sêco } \\ \mathrm{PO}_{4}^{-3}= & 0,30 \text { e.mg por } 100 \mathrm{~g} \text { de solo sêco (solúvel em áci- } \\ & \text { do oxálico }+ \text { oxalato de potássio) }\end{array}$

A área utilizada achava-se em alqueive há seis anos, sem nenhuma cultura. Apresentava vegetação uniforme de capim gordura (Melinis minutiflora Beauv).

O delineamento experimental foi o de bloco ao acaso, com 12 tratamentos e 6 repetições. Onze diferentes modalidades de aplicação de massa vegetal foram comparadas:

$A=$ Testemunha, sem aplicação de matéria orgânica

$B=$ Capim gordura sêco incorporado ao solo

$C=$ Soja perene (Glycine javanica L.) sêca, incorporada ao solo

$D=$ Palha de arroz (Oryza sativa L.), incorporada ao solo

$E=$ Capim gordura verde, incorporado ao solo

$F=$ Soja perene fresca, incorporada ao solo

$G=$ Palha de arroz fresca, incorporada ao solo

(2) Análise do solo feita pela Seç̃o de Quimica do Instituto Agronômico de Campinas. 
$H=$ Capim gordura sêco mais soja perene sêca, incorporados ao solo

$I=$ Capim gordura sêco mais soja perene sêca, meia dose de cada, incorporados ao solo

$J=$ Capim gordura sêco, aplicado ao solo, em cobertura morta (mulch)

$K=$ Soja perene sêca, aplicada ao solo, em cobertura morta (mulch)

$L=$ Estêrco de curral, bem curtido, incorporado ao solo

Todos êsses materiais (palha de arroz, soja perene e capim gordura), quando secos, foram aplicados na base de $1 \mathrm{t} / \mathrm{ha}$, equivalentes a uma dose de massa vegetal. As massas vegetais frescas foram aplicadas na base de $35 \mathrm{t} / \mathrm{ha}$. Os materiais secos correspondem àqueles que haviam sido cortados cêrca de dois meses antes da aplicação, e as massas verdes, àquelas cortadas à véspera do plantio. $O$ estêrco foi empregado na base de $10 \mathrm{t} / \mathrm{ha}$.

Todo o campo experimental foi adubado com 100 e $50 \mathrm{~kg} / \mathrm{ha}$, respectivamente, de $\mathrm{P}_{2} \mathrm{O}_{5}$ e $\mathrm{K}_{2} \mathrm{O}$, na forma de superfosfato simples e cloreto de potássio. A adubação nitrogenada, em forma de sulfato de amônio, foi feita na base de $40 \mathrm{~kg} / \mathrm{ha}$ de $\mathrm{N}$, apenas nos blocos II, IV e V. Êsse adubo azotado foi aplicado metade em cobertura, aos 5 dias, e a outra metade, 20 dias após a germinação do feijoeiro.

No mesmo dia do plantio de feijão, a 17 de março de 1965, abriram-se em todo o terreno sulcos espaçados de $40 \mathrm{~cm}$, com profundiade aproximada de $15 \mathrm{~cm}$, nos quais foram colocadas as massas vegetais correspondentes aos diversos tratamentos. Nesses mesmos sulcos foi aplicada a mistura de adubos fosfatados e potássico. Para cobrir a massa vegetal e adubos químicos foram abertos sulcos à cêrca de $3 \mathrm{~cm}$, ao lado, os quais foram aproveitados para a semeação do feijão. O espaçamento entre linhas foi de $40 \mathrm{~cm}$, e de $15 \mathrm{~cm}$ a distância entre covas, na linha. Cada cova recebeu duas sementes. Empregou-se a variedade Pintado. Não se fêz desbaste.

\section{3 - RESULTADOS OBTIDOS}

\section{1 - EFEITOS FÍSICOS}

O tempo foi favorável na fase inicial do experimento. A germinação se deu dentro de uma semana, tendo sido os "stands" finais satisfatórios. Aos 12 dias após a germinação iniciou-se pequena estiagem, de duas semanas, que prejudicou ligeiramente o desenvolvimento das plantas.

Durante tôda a fase de vegetação, foram registradas as temperaturas dos canteiros de alguns tratamentos. Determinaram-se 
também os teores de umidade do solo, em canteiros de alguns tratamentos, no período em que as plantas do feijoeiro exibiam sintomas de falta de água.

\subsection{1 - TEMPERATURA DO SOLO}

Foram empregados dois teletermógrafos "Foxboro", com duas penas cada, para registrar as temperaturas do solo, em diferentes canteiros. Foram feitas determinações em canteiros dos tratamentos: $A$ - Testemunha, sem matéria orgânica; $B$ - Capim gordura sêco, incorporado ao solo; $H$ - Capim gordura sêco + soja perene sêca, em.partes iguais, incorporados, e $J$ - cobertura morta de capim gordura sêco. Foram feitas as determinações apenas nestes tratamentos porque não se dispunha de termógrafos em número suficiente, recaindo a escolha dos tratamentos naqueles mais típicos.

Os bulbos sensíveis dos teletermógrafos foram postos a $5 \mathrm{~cm}$ de profundidade no solo e à meia distância entre a massa vegetal e a linha de feijoeiros.

Com os dados termométricos foi elaborado o gráfico da figura 1, indicando as temperaturas máximas e mínimas absolutas, em períodos de 5 dias.

O período compreendido entre os dias 1 a 20 de abril se apresentou sem chuvas e com elevadas temperaturas.

Como se observa na figura 1 , a temperatura máxima no tratamento $A$ - testemunha, sem a proteção da massa vegetal, alcançou cêrca de $49^{\circ} \mathrm{C}$ no período crítico de 10 a 20 de abril. A temperatura mínima nesse período caiu a $14^{\circ} \mathrm{C}$. A amplitude térmica diária máxima nesse período chegou a cêrca de $35^{\circ} \mathrm{C}$.

0 tratamento $J$, com cobertura morta de capim gordura, como era de esperar, apresentou as menores amplitudes diárias de temperaturas. No mesmo período crítico da estiagem a temperatura máxima foi de $28^{\circ} \mathrm{C}$, e mínima de $18^{\circ} \mathrm{C}$. A maior amplitude térmica atingiu apenas $10^{\circ} \mathrm{C}$.

Os tratamentos $B$ - incorporação de capim gordura sêco - e $H$ - incorporação de capim gordura sêco com soje perene sêca apresentaram as temperaturas máximas absolutas intermediárias às dos tratamentos $A$ e $J$. As temperaturas mínimas absolutas pouco diferiram das do tratamento $J$ - cobertura morta de capim gordura. As amplitudes térmicas diárias máximas foram de $13,3^{\circ} \mathrm{C}$ e $17^{\circ} \mathrm{C}$, respectivamente, nos tratamentos $B$ e $H$.

\subsection{2 - UMIDADE DO SOLO}

No dia 19 de abril, quando as plantas apresentavam grandes efeitos da falta de água, foram retiradas amostras de terra das 
linhas junto às plantas, para determinação de umidade. Foram amostradas terras dos tratamentos: $A$ - Testemunha; $E-$ Incorporação de capim gordura verde; $I$ - Incorporação de capim gordura sêco com soja perene; e $F$ - Incorporação de soja perene verde.

A fim de verificar se a incorporação de matéria orgânica (por exemplo capim gordura) altera a capacidade de retenção de água do solo e sua disponibilidade, foram determinadas a capacidade de campo e umidade de murchamento das amostras de solo tiradas dos canteiros testemunha e com incorporação de capim gordura. O resultado dessas determinações encontra-se no quadro 1.

QUADro 1. - Valores das constantes hidricas do solo dos tratamentos testemunha e com incorporação de capim gordura

\begin{tabular}{r|r|r|r|r|r}
\hline Tra ta me n to s & $\begin{array}{c}\text { Umidade } \\
\text { atual } \\
\text { do } \\
\text { solo }\end{array}$ & $\begin{array}{c}\text { Máxima } \\
\text { capaci- } \\
\text { dade de } \\
\text { campo }\end{array}$ & $\begin{array}{c}\text { Umidade } \\
\text { de } \\
\text { murcha- } \\
\text { mento }\end{array}$ & $\begin{array}{c}\text { Disponi- } \\
\text { bilidade } \\
\text { atual de } \\
\text { água }\end{array}$ & $\begin{array}{c}\text { Disponi- } \\
\text { bilidade } \\
\text { máxima } \\
\text { de água }\end{array}$ \\
\hline A- Testemunha ........... & 16,4 & 24,8 & 15,6 & 0,8 & $\%$ \\
$E$ - Capim gordura .......... & 17,8 & 26,8 & 15,9 & 1,9 & 10,9 \\
\hline
\end{tabular}

\section{2 - EFEITOS QUIMICOS}

Aos 45 dias de idade do feijoeiro, foram coletadas amostras de solo dos canteiros dos tratamentos: $A$ - Testemunha; $C$ - Soja perene; $D$ - palha de arroz sêca; $E$ - capim gordura fresco; $F$ - soja perene fresca - e também amostras de fôlhas do feijoeiro da bordadura dos canteiros de todos os tratamentos, para análise.

\subsection{1 - ANALISES DO SOLO ( $\left.{ }^{3}\right)$}

Resultados da análise química do solo encontram-se no quadro 2. Os dados obtidos se apresentaram muito variados. Alguns elementos apresentavam teores muito elevados, indicando ter havido influência dos adubos colocados nos sulcos próximos.

Os resultados analíticos indicaram, entretanto, acentuadas diferenças nos teores de fósforo entre tratamentos em relação à tes- 
QUADRo 2. - Resultados da análise química do solo - dados médios de 6 repetiçōes (1)

\begin{tabular}{|c|c|c|c|c|c|}
\hline Tratamentos & $\mathrm{pH}$ & $\begin{array}{c}\mathrm{N} \\
\text { total }\end{array}$ & $\mathrm{PO}_{4}^{---}$ & $\mathrm{Ca}++$ & $\mathbf{K}^{+}$ \\
\hline & & $\%$ & e. $m g$ & e. $m g$ & $e . m g$ \\
\hline$A$ - Testemunha .. & 4,32 & 0,16 & 0,26 & 1,90 & 0,10 \\
\hline$C$ - Soja perene sêca & 4,22 & 0,15 & 0,42 & 2,17 & 0,25 \\
\hline$D$ - Palha de arroz & 4,32 & 0,15 & 0,49 & 1,85 & 0,17 \\
\hline$E$ - Capim gordura verde & 4,12 & 0,15 & 0,41 & 1,53 & 0,15 \\
\hline$F-$ Soja perene verde $\ldots \ldots \ldots$ & 4,22 & 0,15 & 0,41 & 1,92 & 0,30 \\
\hline D.M.S. (Tukey 5\%) & - & 一 & $\longrightarrow$ & - & 0,15 \\
\hline
\end{tabular}

(1) Análises feitas na Seção de Quimica do Instituto Agronômico.

temunha sem matéria orgânica, não havendo significância nas diferenças.

Para o caso do potássio a análise revelou diferença significativa. Os tratamentos com incorporação de soja perene, sêca ou verde, acusaram teores significativamente maiores de potássio no solo, em relação à testemunha.

\section{2 .2 - ANALISE FOLIAR}

Resultados da análise foliar $\left({ }^{4}\right)$ encontram-se nos quadros 3 e 4. Não acusaram diferenças significativas nos teores de fósforo, nitrogênio e magnésio entre os diversos tratamentos. Mostraram, porém, diferenças significativas para os teores de potassio. O teste de Tukey a $5 \%$, mostrou que o tratamento $C$ - Soja perene sêca, não diferiu significativamente dos tratamentos $F$ - soja perene fresca, $E$ - capim gordura fresco, $K$ - "mulch" de soja perene sêca, e do $H$ - capim gordura + soja perene. Foi porém, superior aos demais tratamentos. O teste de Dunnett a $5 \%$, mostrou que, à exceção do estêrco e do capim gordura sêco, todos os demais tratamentos foram superiores ao testemunha. Os tratamentos correspondentes às leguminosas foram superiores aos correspondentes às gramíneas (teste de Scheffé $5 \%$ ). 
QUADRo 3. - Teores de elementos encontrados nas fôlhas do feijoeiro ( ${ }^{1}$ ) colhidas dos diferentes tratamentos estudados. Tôda a matéria orgânica foi incorporada ao solo, menos nos tratamentos com "mulch"

\begin{tabular}{|c|c|c|c|c|c|}
\hline Tratamentos & $\mathrm{N}$ & $\mathbf{P}$ & K & $\mathrm{Ca}$ & $\mathrm{Mg}$ \\
\hline & $\%$ & $\%$ & $\%$ & $\%$ & $\%$ \\
\hline A - Testemunha & $\mathbf{3 , 7 3}$ & 0,240 & 0,90 & 0.76 & 0,50 \\
\hline$B$ - Capim gordura sêco .. & 3,66 & 0,235 & 1,24 & 0,72 & $u, a t$ \\
\hline$C$ - Soja perene sêca & 3,89 & 0,219 & 2,98 & $0,50 \overline{0}$ & 0,37 \\
\hline$D$ - Palha de arroz sêca ... & 3,71 & 0,218 & 2,03 & 0,59 & 0,47 \\
\hline$E$ - Capim gordura verde .. & 3,94 & 0,238 & 1,83 & 0,62 & 0,53 \\
\hline $\boldsymbol{F}$ - Soja perene verde $\ldots \ldots \ldots$ & 3,82 & 0,217 & 2,43 & 0,60 & 0,43 \\
\hline$G$ - Palha de arroz verde $\ldots$. & 3,77 & 0,239 & 2,20 & 0,62 & 0,48 \\
\hline $\begin{array}{r}H \text { - Capim gordura sêco com } \\
\text { soja perene sêca } \ldots \ldots \ldots\end{array}$ & 3,87 & 0,230 & 2,33 & 0,58 & 0,41 \\
\hline $\begin{array}{r}I \text { - Capim gordura sẻco com } \\
\text { soja penere ( } 1 / 2 \text { dose }) \ldots\end{array}$ & 3,65 & 0,221 & 2,21 & 0,63 & 0,48 \\
\hline$J$ - Mulch capim gordura sêco & 3,84 & 0,238 & 1,96 & 0.69 & $0,4 \mathrm{k}$ \\
\hline$K$ - Mulch soja perene sêca & 3,97 & 0,258 & 2,40 & 0,74 & 0,47 \\
\hline$L$ - Estêrco $\ldots \ldots \ldots \ldots \ldots \ldots$ & 3,72 & 0,241 & 1,12 & 0,66 & 0,59 \\
\hline
\end{tabular}

(1) Análises foram feitas no Laboratório de Análise Foliar do Instituto Agronómico de Campinas.

Examinando os dados referentes ao adubo azotado aplicado em cobertura, não se observaram diferenças significativas sôbre os que não receberam essa adubação. Não houve, também, interação dos tratamentos estudados com a adubação azotada em cobertura.

\section{3 - EFEITOS BIOLOGICOS \\ 3.3.1 - FORMAÇA DE NÓDULOS}

Embora não tivesse sido feita a inoculação de Rhizobium, aos 45 dias de idade foram tomadas 10 plantas de feijoeiro, da bordadura dos canteiros de todos os tratamentos, para exame do grau de formação de nódulos. O resultado da contagem é apresentado no quadro 4. Não se observou correlação entre número de nódulos e produção, mas observou-se certa tendência para formação de maior número de nódulos nos tratamentos que receberam a incorporação de gramíneas, em relação aos que receberam leguminosas. A cobertura morta proporcionou aumento de nodulação independentemente do tipo de massa vegetal. 
QUADro 4. - Teores de potássio nas fôlhas, produçōes de sementes e respectivas massas vegetais de feijão, correspondentes aos diferentes tratamentos

\begin{tabular}{|c|c|c|c|c|}
\hline \multirow{2}{*}{ Tratamentos } & \multirow{2}{*}{$\begin{array}{l}\text { Teor } \\
\text { de } \\
\text { potássio } \\
\text { nas } \\
\text { fôlhas }\end{array}$} & \multicolumn{2}{|c|}{ Producão de } & \multirow{2}{*}{$\begin{array}{l}\text { Número } \\
\text { médio } \\
\text { de } \\
\text { nódulos }\end{array}$} \\
\hline & & $\begin{array}{l}\text { massa } \\
\text { vegetal }\end{array}$ & sementes & \\
\hline & $\%$ & $\kappa g / h a$ & $\mathrm{~kg} / \mathrm{ha}$ & \\
\hline$A$ - Testemunha $\ldots \ldots \ldots \ldots \ldots \ldots$ & 0,90 & 4.050 & 154 & 11,5 \\
\hline$L$ - Estêrco $\ldots \ldots \ldots \ldots \ldots \ldots \ldots \ldots \ldots$ & 1,12 & 4.150 & 250 & 10,1 \\
\hline GRAMÍNEAS & & & & \\
\hline$B$ - Capim gordura seco & 1,24 & 4.500 & 321 & 11,4 \\
\hline$E-$ Capim gordura verde $\ldots \ldots \ldots \ldots$ & 1,83 & 4.700 & 379 & 9,6 \\
\hline$D$ - Palha de arroz sêca & 2,03 & 5.050 & 242 & 13,3 \\
\hline$G$ - Palha de arroz verde $\ldots \ldots$ & 2,20 & 5.670 & 333 & 13,2 \\
\hline$J$ - Mulch de capim gordura sêcc $\ldots$. & 1,96 & 6.400 & 438 & 13,0 \\
\hline GRAMÍNEA E LEGUMiNOSA & & & & \\
\hline $\begin{array}{r}H-\text { Capim gordura sêco }+ \text { soja perene } \\
\text { sêca } \ldots \ldots \ldots \ldots \ldots \ldots \ldots \ldots \ldots \ldots\end{array}$ & 2,32 & 5.600 & 450 & 11,5 \\
\hline sêca $(1 / 2$ dose $) \quad \ldots \ldots \ldots \ldots \ldots \ldots$ & 2,21 & 5.350 & 400 & 17,6 \\
\hline LEGUMINOSAS & & & & \\
\hline$K$ - Mulch de soja perene sêca & 2,40 & 6.650 & 633 & 14,7 \\
\hline$C$ - Soja perene séca $\ldots \ldots \ldots \ldots$ & 2,98 & 6.070 & 625 & 7,7 \\
\hline$F$ - Soja perene verde & 2,43 & 7.520 & 608 & 10,4 \\
\hline (Tukey $5 \%$ ) & 0,76 & 2.572 & 350 & 5,6 \\
\hline D.M.S. (Dunnett $5 \%$ ) ..... & 0,56 & 1.920 & 261 & 一 \\
\hline$\left(\right.$ Scheffé) ${ }^{(1)} \quad \ldots \ldots$ & * & $\rightarrow$ & * & - \\
\hline
\end{tabular}

(1) O teste de Scheffé foi aplicado na incorporação entre os grupos de tratamentos com gramíneas e com leguminosas.

\subsection{2 - MASSA VEGETAL}

$\mathrm{Na}$ ocasião da tomada de amostras para análise foliar, foram arrancadas dez plantas de bordaduras dos canteiros de cada tratamento, e pesadas, a fim de estimar o volume de massa vegetal. Êsses dados transformados em $\mathrm{kg} / \mathrm{ha}$ se encontram no quadro 4 . A análise estatística mostrou que o tratamento $F$ - soja perene verde, foi superior (teste Tukey $5 \%$ ) aos tratamentos $A$ - tes- 
temunha, $L$ - estêrco, $D$ - capim gordura fresco. Os tratamentos $F$ - soja perene fresca, $C$ - soja perene sêca, $H$ - "mulch" de capim gordura sêco, e $K$ - "mulch" de soja perene sêca, foram superiores ao testemunha (teste de Dunnett a 5\%). As produções médias de massa verde dos tratamentos que receberam leguminosas foram sempre maiores que as dos tratamentos que receberam gramíneas. As diferenças não foram, porém, significativas pelo teste de Scheffé $5 \%$. O coeficiente de variação foi de $26 \%$.

\subsection{3. - SISTEMA RADICULAR}

O estudo do sistema radicular do feijoeiro foi executado a 20 de maio, quando as plantas estavam com 58 dias de idade.

Os tratamentos estudados foram: $A$ - testemunha, $B$ - capim gordura sêco, incorporado, $C$ - soja perene sêca, incorporada, $D$ - palha de arroz sêca, incorporada, e $J$ - "mulch" de capim gordura sêco.

QUADRo 5. - Quantidades de raízes de feijoeiro e de matéria orgânica, esta aplicada 45 dias antes do plantio, encontradas nas camadas de $0-10$ e $10-20 \mathrm{~cm}$ de profundidade no solo, após a colheita, em alguns tratamentos

\begin{tabular}{|c|c|c|c|c|c|}
\hline \multirow{2}{*}{$\begin{array}{l}\text { Tratamentos - aplica- } \\
\text { ção de matéria orgânica }\end{array}$} & \multirow{2}{*}{$\begin{array}{l}\text { Camadas } \\
\text { do solo }\end{array}$} & \multicolumn{2}{|c|}{$\begin{array}{c}\text { Raizes } \\
\text { encontradas }\end{array}$} & \multicolumn{2}{|c|}{$\begin{array}{l}\text { Matéria orgânica } \\
\text { encontrada }\end{array}$} \\
\hline & & $\begin{array}{c}\text { Por } \\
\text { camada }\end{array}$ & $\begin{array}{l}\text { Acumu- } \\
\text { Iadas }\end{array}$ & $\begin{array}{c}\text { Por } \\
\text { camada }\end{array}$ & $\begin{array}{l}\text { Acumu- } \\
\text { ladas }\end{array}$ \\
\hline & & $g$ & $g$ & $g$ & $g$ \\
\hline A -- Testemunha & $\begin{array}{l}0-10 \mathrm{~cm} \ldots \ldots \\
10-20 \mathrm{~cm} \ldots\end{array}$ & $\begin{array}{l}7,16 \\
1,40\end{array}$ & $\ddot{8,56}$ & $\begin{array}{r}21,2 \\
2,9\end{array}$ & $\overline{24,1}$ \\
\hline $\begin{array}{c}B \text { - Capim gordura sêco, } \\
\text { incorporado } \ldots . . .\end{array}$ & $\begin{array}{l}0-10 \mathrm{~cm} \ldots \\
10-20 \mathrm{~cm} .\end{array}$ & $\begin{array}{l}5,67 \\
1,09\end{array}$ & $\overrightarrow{676}$ & $\begin{array}{r}112,0 \\
2,6\end{array}$ & $\overline{114,6}$ \\
\hline $\begin{array}{c}C \text {-- Soja perene sêca, in- } \\
\text { corporada } \ldots \ldots \ldots .\end{array}$ & $\begin{array}{l}0-10 \mathrm{~cm} \\
10-20 \mathrm{~cm}\end{array}$ & $\begin{array}{r}11,28 \\
1,27\end{array}$ & $\overrightarrow{12,55}$ & $\begin{array}{r}98,4 \\
1,9\end{array}$ & $10 \overline{0,3}$ \\
\hline $\begin{array}{c}D \text { - Palha de arroz sêca, } \\
\text { incorporada } \ldots . . . .\end{array}$ & $\begin{array}{l}0-10 \mathrm{~cm} \ldots \ldots \\
10-20 \mathrm{~cm} \ldots\end{array}$ & $\begin{array}{l}8,37 \\
1,47\end{array}$ & $\overrightarrow{9,84}$ & $\begin{array}{r}28,5 \\
2,9\end{array}$ & $\overrightarrow{21,4}$ \\
\hline$F-\begin{array}{c}\text { Soja perene verde, } \\
\text { incorporada } \ldots . . .\end{array}$ & $\begin{array}{l}0-10 \mathrm{~cm} \ldots \ldots \\
10-20 \mathrm{~cm} \ldots\end{array}$ & $\begin{array}{r}18,16 \\
3,04\end{array}$ & $21 \overrightarrow{20}$ & $\begin{array}{l}70,3 \\
10,8\end{array}$ & $\overrightarrow{81,1}$ \\
\hline $\begin{array}{r}J-\text { Capim gordura sêco, } \\
\text { em cobertura ...... }\end{array}$ & $\begin{array}{l}0-10 \mathrm{~cm} \ldots \\
10-20 \mathrm{~cm} .\end{array}$ & $\begin{array}{l}3,27 \\
0,98\end{array}$ & $\overrightarrow{4,25}$ & $\begin{array}{r}16,4 \\
3,7\end{array}$ & $\overrightarrow{20,1}$ \\
\hline
\end{tabular}


Para cada tratamento, foram extraídos 40 blocos de terra com as raízes. Os blocos tiveram a seguinte dimensão: $10 \times 10$ $\times 10 \mathrm{~cm}$.

Tomaram-se nos canteiros de cada tratamento, numa área de $50 \times 40 \mathrm{~cm}$, três plantas em linha, bastante uniformes. Da primeira camada do solo, com $10 \mathrm{~cm}$ de profundidade, foram retirados 20 blocos de terra, o que também foi feito na segunda camada, entre 10 e $20 \mathrm{~cm}$. O método na extração das raízes foi o empregado por Franco e Inforzato em cafeeiros (3), com algumas modificações. Os pesos das raízes e da matéria orgânica dos blocos de terra das profundidades de $0-10$ e $10-20 \mathrm{~cm}$ dos tratamentos estudados, acham-se no quadro 5.

Ao examinar as massas vegetais incorporadas notou-se haver decomposição mais rápida das fôlhas de leguminosas que as das gramíneas.

As maiores quantidades de raízes, nas profundidades de $0-10$ e 10-20 $\mathrm{cm}$ do solo, foram encontradas no tratamento $F$ - soja perene fresca. A natureza do material incorporado ao solo influiu consideràvelmente no desenvolvimento do sistema radicular do feijoeiro. Assim, o tratamento $B$ - incorporação de capim gordura, trouxe diminuição de $70 \%$ nas raizes do feijoeiro, apesar de ter apresentado $40 \%$ a mais de matéria orgânica no solo, em relação ao tratamento $F$ - soja perene fresca. Convém destacar que o tratamento "mulch" de capim gordura também resultou em redução de raízes, para cêrca da metade das obtidas do testemunha.

\section{3 .4 - SEMENTES}

Procedeu-se à colheita do feijão a 7 de junho. Na ocasião foi feita a contagem de "stands" finais. Os números de plantas não diferiram estatìsticamente, entre tratamentos, à exceção dos canteiros-testemunha, que apresentaram "stands" bastante inferiores. A inspeção feita quase que diàriamente, permitiu verificar que a falta de umidade no solo contribuiu muito para a morte de plantas nos canteiros-testemunha.

A análise estatística dos dados de produção de sementes de feijão, não mostrou diferenças significativas entre blocos adubados com nitrogênio em cobertura e aquêles que não receberam essa adubação.

As produções médias de sementes de feijão em $\mathrm{kg} / \mathrm{ha}$ encontram-se no quadro 4. A análise estatística mostrou diferenças altamente significativas entre os pesos de sementes dos tratamentos estudados. O coeficiente de variação foi de $31 \%$.

0 teste de Tukey a 5\%, para comparar as médias dos pesos de sementes, indicou que o tratamento $K$ - "mulch" de soja perene fresca, foi superior aos tratamentos $A$ - testemunha, $L$ - estêrco, e $B$ - incorporação de soja perene sêca. 0 mesmo teste 
indicou que $F$ - incorporação de soja perene fresca, foi superior aos tratamentos $A$ - testemunha, e $L$ - incorporação de estêrco.

$\mathrm{O}$ teste de Dunnett $5 \%$ permitiu verificar que os tratamentos $K$ - "mulch" de soja perene sêca, $C$ - incorporação de soja perene sêca, $F$ - incorporação de soja perene fresca, $H$ - incorporação de capim gordura. + soja perene sêca, e $J$ - "mulch" de capim gordura sêco, foram superiores ao tratamento $A$ - Testemunha.

A incorporação de massa vegetal leguminosa proporcionou maior produção de sementes de feijão em relação à incorporação de massa vegetal de gramíneas. Essa diferença foi significativa a $5 \%$, pelo teste de Scheffé.

\section{4 - CORRELAÇõES ENTRE OS FATÔRES ESTUDADOS}

Estudaram-se as correlações entre os fatôres: teor de potássio nas fôlhas do feijoeiro e produção de massa vegetal; teor de potássio nas fôlhas e a produção de sementes; produção de massa vegetal e produção de sementes. Todos os coeficientes de correlação, mostraram-se altamente significativos, sendo seus valores respectivamente de: $+0,78 * *,+0,82 * *$ e $+0,85 * *$.

Foram estudadas, também, correlações entre números de nódulos e produção de sementes e número de nódulos e produção de massa vegetal de feijoeiro. Os coeficientes encontrados não foram, porém, significativos.

\section{5 - DISCUSSÃO E CONCLUSÕES}

Como o feijoeiro é planta delicada, dotada de sistema radicular superficial, os efeitos físicos, físico-químicos e biológicos, nêle provocados pelos tratamentos, se fizeram sentir de uma maneira surpreendente.

Camargo e outros (2), Medcalf (7), mostraram que a cobertura morta atenua as variações extremas de temperatura do solo. Os dados obtidos dêste experimento, relativos a variação de temperatura, mostxam que a incorporação da massa vegetal também contribuiu decisivamente para amenizar a variação diária da temperatura do solo, embora em escala mais moderada que a cobertura morta.

Grohmann \& Medina (5) verificaram que as camadas superficiais, de 0 a $30 \mathrm{~cm}$, do solo terra-roxa-legítima de mata, retêm mais água que as camadas inferiores, principalmente sob as tensões menores que 3 atmosferas, e que os solos de mata mantêm mais umidade nas camadas correspondentes às dos mesmos tipos de solo já bastante cultivados. Aquêles autores atribuem essa melhor retenção de água ao maior conteúdo de matéria orgânica existente nas camadas superficiais do solo de mata. 
Embora as observações tenham sido feitas em caráter preliminar, os dados obtidos neste experimento mostram que o tratamento "incorporação de capim gordura" parece contribuir para aumentar a retenção de água do solo.

Dada a pequena capacidade de aproveitamento da umidade do solo, própria do sistema radicular do feijoeiro, podem os índices de umidade do solo, próximos do ponto de murchamento, no tratamento testemunha, explicar o efeito favorável da incorporação de massa vegetal no feijoal.

Medcalf (7) mostrou que a cobertura morta com capim colonião (Panicum maximum L.), no decorrer do tempo, provocou elevação do $\mathrm{pH}$, do teor de matéria orgânica, bem como de potássio, cálcio e fósforo do solo. Neste experimento, os dados obtidos não mostraram os mesmos resultados. Provàvelmente, o tempo decorrido entre a tomada da amostra e o exame de laboratório foi insuficiente, de apenas dois meses e, portanto, muito menor que o decorrido no experimento de Medcalf. $O$ único elemento que aqui se evidenciou no solo, encontrando-se em maior dose estatìsticamente significativa, foi o potássio. Aliás, Aslander já salientou êsse fato em seu trabalho (1). Segundo êsse pesquisador, a matéria orgânica (adubo verde de gramínea) pode favorecer a solubilização do potássio e a assimilação pela planta dêsse elemento. O nível do elemento fósforo também aumentou, porém as médias apresentadas foram de dados bastante variados que estatìsticamente não chegaram a acusar diferença significativa entre os tratamentos estudados, inclusive testemunha.

A incorporação de massa de gramínea, parece ter beneficiado o feijoeiro, com relação apenas aos efeitos físicos e formação de nódulos. Amenizou a variabilidade térmica do solo, manteve maior umidade, em relação ao do testemunha, e proporcionou condições no solo propícias à maior formação de nódulos. Isto permite explicar, porque a massa de graminea, com relação $\mathrm{C} / \mathrm{N}$ alta, necessita de nitrogênio para decomposição (4). As bactérias que promovem decomposição da matéria orgânica concorrem com a planta em nitrogênio do solo. Essa condição (deficiência de azôto no solo) parece estimular a atividade do Rhizobium phaseoli, embora não contribuindo para maior desenvolvimento e produção do feijoeiro.

A incorporação de massa de leguminosa proporcionou melhores condições quanto aos aspectos físicos e químicos, trazendo melhor desenvolvimento vegetativo. A mineralização do nitrogênio das leguminosas, no geral com relação $\mathrm{C} / \mathrm{N}$ baixa, apresentou-se bem mais rápida, podendo ocorrer dentro de uma ou duas semanas, dependendo da temperatura do ambiente, especialmente no caso de massa formada de fôlhas e caules mais tenros. Outras partes lenhosas, isto é, caules e raízes, podem ter desempenhado o papel de regulador de temperatura do solo. 
No presente trabalho, embora as observações do ponto de vista físico tenham sido feitas apenas em alguns tratamentos, os dados obtidos possibilitaram as seguintes informações:

a) Durante o período de estiagem, ao mesmo tempo que o canteiro testemunha, a $5 \mathrm{~cm}$ de profundidade no solo, apresentou temperatura máxima absoluta de $48^{\circ} \mathrm{C}$, no canteiro com "mulch", nas mesmas condições, a temperatura não foi além de $27^{\circ} \mathrm{C}$, ou seja, $21^{\circ} \mathrm{C}$ a menos. Nesse mesmo período, os tratamentos $B-$ incorporação de capim gordura sêco, e $H$ - incorporação conjunta de capim gordura e soja perene secos, apresentavam as temperaturas absolutas máximas intermediárias de $32,5^{\circ} \mathrm{C}$ e $35^{\circ} \mathrm{C}$, mostrando também desempenhar bom papel como protetor do solo, embora inferior ao do "mulch".

As amplitudes de variações de temperaturas dos tratamentos citados, mostram também ser enorme o papel de moderador da variação térmica do solo, desempenhado pelo "mulch". Neste, a amplitude geotérmica diária foi de apenas $8^{\circ} \mathrm{C}$, quando no testemunha, sem proteção, alcançou $32^{\circ} \mathrm{C}$. Nos canteiros com incorporação de matéria orgânica, notou-se também acentuado efeito moderador. Nos canteiros dos tratamentos $B$ e $H$, as amplitudes térmicas diárias foram, respectivamente, de $11,5^{\circ} \mathrm{C}$ e $16^{\circ} \mathrm{C}$.

b) A incorporação de massa vegetal contribuiu para manter maior umidade do solo, em relação à do testemunha.

c) Os números de nódulos formados nos diversos tratamentos não corresponderam à variação da produção de sementes. Observou-se tendência de formação de maior número de nódulos nos tratamentos com incorporação de gramíneas em relação aos que receberam a incorporação de leguminosas.

d) A incorporação de soja perene, fresca ou sêca, contribuiu para aumentar a disponibilidade de potássio do solo, e isto, provàvelmente, proporcionou aumento do teor de potássio nas fôlhas do feijoeiro. Êsse aumento foi altamente significativo nos tratamentos que receberam soja perene, quer incorporada, quer em cobertura.

e) A aplicação de adubo nitrogenado, nas condições do experimento, não alterou o comportamento dos tratamentos estudados. A umidade proporcionada pela incorporação de matéria orgânica talvez não tenha sido suficiente para solubilizar o nitrogênio aplicado. Por essa razão, a falta de umidade do solo não teria propiciado a nenhum dos tratamentos a assimilação do elemento $\mathrm{N}$ pelas plantas.

f) A aplicação de massa vegetal em incorporação ao solo ou em cobertura morta, em diferentes modalidades (gramínea, legu- 
minosa ou gramínea com leguminosa), proporcionou maior desenvolvimento da planta em relação à testemunha. A incorporação de leguminosa, trouxe maior desenvolvimento vegetativo do feijoeiro, em relação à incorporação de gramínea.

g) A incorporação de soja perene fresca foi o tratamento que proporcionou maior desenvolvimento das raízes do feijoeiro. A qualidade da massa orgânica incorporada teve grande influência no desenvolvimento do sistema radicular do feijoeiro. Embora o canteiro do tratamento $B$ - capim gordura incorporado, tenha apresentado, na ocasião do exame, maior quantidade de massa orgânica incorporada ao solo que o do tratamento $F$ - soja perene fresca, êste último proporcionou maior desenvolvimento radicular que aquêle tratamento.

Normalmente, o desenvolvimento do sistema radicular esteve ligado ao da vegetação aérea. Não obstante, o tratamento $J$ "mulch" de capim gordura sêco comportou-se de maneira irregular, pois, embora tenha proporcionado maior vegetação aérea, não trouxe, aparentemente, maior desenvolvimento do sistema radicular do feijoeiro.

h) A incorporação ou a cobertura de massa vegetal, proporcionou, via de regra, aumentos de produção de sementes, porém, apenas a incorporação de leguminosa trouxe aumentos significativos.

i) Entre as correlações estudadas, aquelas entre o teor de potássio nas fôlhas e a produção de massa vegetal, entre o teor de potássio nas fôlhas e a produção de sementes e entre a produção de massa vegetal e a produção de sementes, acusaram coeficientes de correlação altamente significativos (1\%). As regressões entre êsses fatôres estudados foram significativas e positivas, mostrando que o maior teor de potássio nas fôlhas proporcionou maior vegetação e maior produção de sementes.

j) A aplicação de estêrco, na base de $10 \mathrm{t} / \mathrm{ha}$, não aumentou significativamente o teor de potássio nas fôlhas do feijoeiro, nem a produção de massa vegetal ou de sementes.

EFFECTS OF THE INCORPORATION OF NON DECOMPOSED ORGANIC MATTER INTO THE SOIL IMMEDIATELY BEFORE PLAN'IING TIME OF DRY BEANS

\section{SUMMARY}

The main objective of the present experiment has been the study of the behavior of organic matter, i. e., non decomposed mass of leguminous 
and gramineous plants when incorporated into the soil right before the planting time of dry beans and its effects.

Data obtained showed that the incorporation of non decomposed plant mass had the following results: (a) moisture was retained in a greater degree and temperature variations were somewhat reduced, although it was in fact less efficient than mulch; (b) there was a tendency of forming a larger number of nodules in the roots, especially when gramineous plants were incorporated, even if this is not directly related to higher productivity; (c) increase in the content of potassium in the leaves, in the development of the plant and root system and in the seed production of dry beans. These effects were particularly significant when soybeans were applied, either incorporated into the soil or as top dressing.

\section{LITERATURA CITADA}

1. Aslander, Alfred \& Armolik, Neeme. Influencia que ejercen los materiales organicos sobre la fijación del potasio en el suelo. Revista de la Potasa, Berna, Sec. 16, Ago. 1965. p.1-2. Separata de Transactions of the Royal Institute of technology, Stockholm, n. ${ }^{\circ} 236$.

2. Camargo, A. P., Ortolani, A. A., Rodriguez, O. \& Godoy, H. Efeito da cobertura de terreno em laranjal sôbre as temperaturas extremas do ar. Bragantia 20:XI-XVII. 1961.

3. FrANCO, C. M. \& INFORZATO, R. O sistema radicular do cafeeiro nos principais tipos de solo do Estado de São Paulo. Bragantia 6:[443]478. 1946.

4. Grohmann, F. \& Medina, H. P. Características de umidade dos principais solos do Estado de São Paulo. Bragantia 21:[285]-295. 1962.

5. Guazelli, R. Resultado de experimento de calagem $\times$ adubo verde. Relatório da Estação Experimental de Patos, Estado de Minas Gerais. 1963.

6. Lyon, T. L., Buckman, H. O. \& Brady, N. C. The nature and properties of soils. New York. The MacMillan Company, 571p. 1950.

7. MedCALf, J. C. Estudos preliminares sôbre aplicação de cobertura morta em cafeeiros novos do Brasil (Boletim n. ${ }^{\circ}$ 12). IBEC Research Institute. 1956.

8. Miyasaka, S. Efeito da incorporação de adubo verde imediatamente antes do plantio de feijão da sêca. II Encontro de Técnicos em Agricultura. Campinas, 25 a 27 de agôsto de 1935.

9. _ - Freire, E. S. \& Mascarenhas, H. A. A. Efeito da matéria orgânica sôbre a produção do feijoeiro. Trabalho apresentado ao $\mathrm{X}$ Congresso Brasileiro de Ciência do Solo. Piracicaba, 19 a 30 de julho de 1965. 